\title{
Comparison of Christensen Prosthesis System with Autogenous Costochondral Graft for Arthroplasty of Traumatic Temporomandibular Joint Dysfunction
}

\author{
Aria Omrani* M.D.
}

\section{INTRODUCTION}

The temporomandibular joint (TMJ) is the only joint in the body that is both a hinge and a sliding joint. The TMJ is the most active joint of the body, moving up to 2000 times each day during talking, chewing, swallowing and snoring. Disorders of the TMJ can be referred biomechanically and neurologically to the upper cervical spine, due to the structural approximation and neuromuscular relationship of the TMJ area and occipitoatlantal area. When TMJ dysfunction occurs in children, it impairs mandibular growth and results in mandibular asymmetry or retrognathism. Temperomandibular joint meniscus malposition frequently produces neck pain, headaches and suboccipital muscle spasms.(1) In many cases TMJ dysfunction has a profoundly negative influence on the psychosocial development of the patient, because of the obvious facial deformity, which worsens with growth. Arthroplasty of the TMJ is an effective treatment for structural disorders. Various alloplastic materials, as well as autogenous grafts, have been used in arthroplasty of the TMJ.

Because of the growing use of both autogenous Costochondral graft (CCG) and alloplastic Christensen prosthesis system, it is important that the potential benefits of both procedures be carefully weighed against their disadvantages in different circumstances. After outlining the anatomy of the normal TMJ and the causes and effects of TMJ dysfunction, this article compares CCG and alloplastic Christensen prostheses in terms of advantages, disadvantages and patient

\footnotetext{
*To whom correspondence should be addressed:Aria Omrani P.O.Box 81655 -1513 Isfahan Iran
}

groups in which their use is most appropriate.

TMJ DYSFUNCTION

Anatomy of the TMJ

The TMJ hinges within the glenoid fossa of the mandible and glides anteriorly to the eminentia during normal motion. The head of the condyle and the glenoid fossa are covered with fibroid cartilage which serves as a shock absorber (1). The meniscus of the TMJ divides the joint cavity into two parts. The lower part is used during gliding motion and the upper part is used for hinge movements. The two heads of the pterygoid muscle act asynchronously to open the joint. One head of the external pterygoid muscle pulls the meniscus forward while the second head opens the joint. Secondary assistance is provided by the mylohyoid, geniohyoid and digastric muscles. In closing the jaw, the temporal, masseter and internal pterygoid muscles are activated.

\section{Causes of TMJ dysfunction}

Temporomandibular joint dysfunction results from various agents including internal drangement, congenital malformation, arthrotic changes, avascular necrosis, rheumatoid arthritis and trauma $(2,3,4,5,6,7)$. Local and systemic infections systemic diseases like rheumatoid arthritis, ankylosing spondylitis and psoriasis are factors which have been implicated in the etiopathogenesis of TMJ ankylosis $(8,9,10,11)$. Trauma conditions have also often been implicated in the etiology of TMJ ankylosis $(12,13,14)$, the presence of intra-articular hematoma with intra-articular damage leads to scarring and bone formation with resultant hypomobility and ankylosis $(11,15)$. The reported 
proportion of cases of TMJ dysfunction due to traums ranges from $26 \%$ to $100 \%(8,9,12,16)$.

\section{Physiology of traumatic TMJ dysfuntion}

Trauma to the TMJ can be caused by a single, acute injury (such as blow to the jaw or car accident) or more prolonged, minor, stress due to, for example, clenching or grinding of the teeth. Temperomandibular trauma results in displacement of the disk of cartilage that cushions the ball-and-socket of the joint with possible resultant entrapment of the disc (17).

In partial displacement of the TMJ, condyle translation is not blocked and when the patient moves the closed jaw forward or toward the contralatral side, the condyle will snap forward into its normal position. In complete displacement, the disc is usually dislodged anteriorly toward the front of the condyle so its translation is restricted when the mouth is opened. Persistent condyle motion on a dislocated disc encourages irregular adaptive remodeling and osteoarthritis to develop within the joint because the dislocated disc can no longer cushion the articular surfaces (1).

\section{Symptoms and signs of traumatic TMJ dysfunction}

Muscle fatigue and a severe dull facial ache that is often localized to an anterior area to the tragus of the ear are the major symptoms of TMJ dysfunction. Muscle spasm in pterygoid, masseter and temporalis; bruxism; tenderness at the proximal mandible; and typical facial neuralgia are some of local effects of TMJ dysfunction.

\section{TMJ RECONSTRUCTION:}

In recent decades, TMJ reconstruction using an autogenous costochondral graft (CCG) has gained popularity, mainly because this graft provides a functional implant with growth potential and restores the joint as closely as possible to its normal anatomy. However, there is a significant proportion of patients, including patients who have had multiple surgery, in whom success rates with autogenous grafts are low. The Christensen TMJ prosthesis system offers a significant improvement in function and reduction in pain in most of these patients. This system involves covering the articulating surface of the temporal bone and replacing the meniscal disc with synthetic prostheses. Careful selection of the treatment modality employed in surgical reconstruction of the TMJ plays a significant role in increasing the success rate of TMJ reconstruction.

\section{AUTOGENOUS COSTOCHONDRAL GRAFT}

The most widely accepted autogenous reconstruction of the TMJ involves a costochondral graft. Ease in obtaining and adapting the graft, biological similarity to the mandibular condyle and regenerative potential are some of advantages of CCG $(18,19,20,21,22,23)$. A CCG can also keep pace with the growth of the unaffected side to maintain mandibular symmetry during the growth period (20).

Kaban et al (1990) achieved a mean maximum postoperative interincisal opening at one year of $37.5 \mathrm{~mm}$ using CCGs to reconstruct the mandibular ramus in treatment of TMJ ankylosis in their seven-step surgical plan. This treatment included aggressive resection of the ankylotic segment, ipsilateral and contralateral coronoidectomy, lining of the joint with temporalis fascia or cartilage reconstruction of the ramus with a CCG and rigid fixation of the graft. $(18,24)$

However, current evidence suggests that CCGs tend to have more vertically directed condylar growth pattern and more laterally positioned condyles than native bone tissue leading to possible mandibular prognathism $(18,25)$. In addition, in patients with arthropathy, long-term steroids can weaken a CCG which may cause ankylosis disease in the reconstructed joint $(27,28)$. Clark and Britton (2001) reported a case of patient who had been operated on three times after a car motor vehicle accident. During the third operation, surgeons attempted to establish TMJ function with a bilateral CCG. This ultimately fused with heterotopic bone, causing diminishing ability to chew and function and progression from fibrous to complete and total bony ankylosis (29).

\section{CHRISTENSEN PROSTHESIS SYSTEM}

The option to use an alloplastic system, instead of an autogenous one, is determined on the basis of severity of disease. The Christensen TMJ fossa-eminence prosthesis system offers a treatment modality for severe TMJ dysfunction especially in patients who have had multiple surgery in whom autografts appear to have a very low success rate $(17,33,34,35)$.

Temporomandibular joint reconstruction with the use of the Christensen alloplastic joint system allows a close reproduction of the natural anatomy (19). The Christensen TMJ fossa-eminence prosthesis systems provide a smooth surface for articulation with the natural condyle or with a Christensen TMJ condylar prosthesis in the case of total joint replacement. The prosthesis is attached to underlying bone structure with $\mathrm{Co}-\mathrm{Cr}$ bone screws. Christensen TMJ condylar protheses are designed to sit against the Christensen TMJ fossa-eminence prosthesis and are secured to the ramus of the mandible. In the case of significant bone loss or trauma, the surgeon may request that the prostheses are cast to fit the specific patient's anatomical structure. In the case of Christensen TMJ condylar prosthesis, the flange portion is always adapted to the patient's anatomy. 
A study by Chase et al (1995) indicated that total joint reconstruction combining placement of a Co-Cr fossaeminence with a polymethylmethacrylate (PMMA) coated condylar prosthesis led to improved function in $85 \%$ to $90 \%$ of patients (17). In a study by Mcload et al (2001), who undertaked hemi-arthroplasty of the TMJ with a fossa-eminence prosthesis, $73 \%$ of patients had considerable improvement in their symptoms post operatively and a further $24 \%$ had some improvement (35).

Hemi-arthroplasty with Cristensen fossa-eminence involves the same procedure as placing the prosthesis during total arthroplasty of the TMJ. Total arthroplasty with Christensen prosthesis is only indicated in patients with considerable condylar disease (35). Total replacement of TMJ may be considered for disorders include rheumatoid arthritis, osteoarthritis, psoriaratic arthritis and ankylosis after trauma.

The Christensen alloplastic joint system decreases the chance of recurrent ankylosis (30). However, particles of alloplastic prostheses at articular surfaces can generate a giant cell foreign body reaction which may cause loosening of the implant, with resultant fracture or displacement $(19,27,28,31,32)$. Lack of growth and complications related to dystrophic bone formation in children and implant fracture caused by the use of inappropriate alloplastic materials are some factors that precludes the use of alloplastic TMJ prostheses $(20,28,30)$. One of the most important aspects of preoperative assessment is condylar disease. Christensen fossa-eminence prosthesis is not used alone where there is a condylar disease such as avascular necrosis, because the condyle will be less adaptable to the new articular surface opposing it.

Speculand et al (2000) studied outcomes in 62 patients who received total prosthetic replacement of the TMJ between 1988 and 1997 (26). The proportion of patients who could eat all food increased from $23 \%$ of the total group preoperatively to $77 \%$ postoperatively. According to this study, preoperatively, $63 \%$ reported severe pain but this number reduced to $5 \%$ postoperatively. Another study by Chase et al (1995) indicated that $82 \%$ of 22 patients with severe TMJ disorders who underwent implant of a Christensen fossa-eminence prosthesis with retention of disc, showed significant improvement in the ability to eat. In addition, inciser opening improved in $77 \%$ of these patients. The rate of significant improvement in their ability to eat in 26 patients who underwent placement of Christensen fossa-eminence without retention of disc was reported to be $96 \%$. In this group, inciser opening improved in $86 \%$ of patients. In both groups, all patients showed a significant decrease in pain post operatively. A further 21 patients underwent, surgical placement of Christensen fossa-eminence prosthesis along with a condylar prosthesis as part of this study. Eighty six percent of patients in this group showed a significant improvement in ability to eat, $96 \%$ showed a significant decrease in pain and $91 \%$ had significantly improved in inciser opening post operatively (17).

Recurrence and relapse are the most common complications associated with release of TMJ ankylosis. Studies have reported that the incidence of re-ankylosis is between $4 \%$ and $31 \%(9,16,36)$. Recurrence is frequently associated with extent of lesion, the release of TMJ ankylosis and surgical technique employed $(16,38,39)$.

\section{CONCLUSION}

Temporomandibular joint dysfunction creates not only functional and aesthetic problems but also interferes with adequate nutrition and oral hygiene measures. The Christensen prosthesis system and the CCG are both accepted arthroplastic methods of TMJ reconstruction in traumatic TMJ dysfunction. Although CCG has been the most popular treatment modality to date, mainly because of accessibility and its adaptability to the TMJ area, recent studies indicate that as surgery frequency goes up, the rate of success of autografts decreases.

Technical workability, functional adaptability and regenerative potential are some of the advantages of autogenous CCG. The growth potential of CCG makes it a suitable implant in children whereas the lack of growth precludes the use of Christensen alloplastic joint system in this population. Long-term treatment with steroids for an arthroplasty may reduce the physical strength of a CCG and may cause further ankylosis decreasing the utility of CCGs in such patients. The use of Christensen alloplastic joint system is determined on the basis of severity of disease and is most helpful in patients with the most severe symptoms before surgery. This system also decreases the chance of recurrent ankylosis.

\section{REFERENCES}

1 Schafer RC, TMJ Trauma and Its Rehabilitation, Oklahoma City ,Associated Chiropractic Academic Press, 1998.

2 Merrill RG. Historical perspectives and comparisons of TMJ surgery for internal disk derangement and arthropathy. J Craniomandib Pract:474-83;1986.

3 Muir CB, Goss AN. The radiologic morphology of painful temporomandibular joints. ORAL SURG ORAL MED ORAL PATHOL 70:335-59;1990.

4 Schellhas KP. Internal derangement of the temporomandibularjoint: radiologic staging with clinical, surgical, and pathologic correlation. Magn Reson Imaging 7:495-515;1989.

5 Schellhas KP, Piper MA, Ornlie MR. Facial skeleton remodeling due to temporomandibular joint degeneration: an imaging study of 100 patients. AJR 155:373-83;1990.

6 Reiskin AB. Aseptic necrosis of the mandibular condyle: a 
common problem? Quintessence Int 2:85-9;1979.

7 Ogus $\mathrm{H}$. Rhematoid arthritis of the temporomandibular joint. $\mathrm{Br}$ J Oral Surg 12;275-84;1975.

8 Adekeye EO. Ankylosis of the mandible: analysis of 76 cases. J Oral Maxillofac Surg41:442-449; 1983

9 El-Sheikh MM. Temporomandibular joint ankylosis: the Egyptian experience. Ann R Coll Surg Engl 81:12-18; 1999.

10 Guven O. A clinical study on temporomandibular joint ankylosis. Auris Nasus Larynx 27:27-33; 2000.

11 Ugboko VI, Amole AO, Olasoji HO, Ndukwe KC, Temporomandibular joint ankylosis: A multicenter nigerian study, The OnLine Journal of Dentistry and Oral Medicine Vol4:No 3:2002 .

12. Obiechina AE, Arotiba JT, Fasola AO. Temporomandibular joint ankylosis in South Western Nigeria. East Afr Med J 76:683-686; 1999.

13 Roychoudhury A, Parkash H, Trikha A. Functional restoration by gap arthroplasty in temporomandibular joint ankylosis: a report of 50 cases. Oral Surg Oral Med Oral Pathol Oral Radiol Endod 87:166-169; 1999.

14 Nitzan DW, Bar-Ziv J, Shteyer A. Surgical management of temporomandibular joint ankylosis type 111 by retaining the displaced condyle and disc. J Oral Maxillofac Surg 56:1133$1138 ; 1998$.

15 Izumi Y, Kino K, Ohmura Y, Waka H, Shubuya T, Amagasa T. Clinico- statistical study of temporomandibular joint ankylosis: etiology and onset age. J Jpn Soc TMJ 6:100-113.;1994

16 Miyamoto H, Kurita K, Ishimaru J-I, Goss AN. A sheep model for temporomandibular joint ankylosis. J Oral Maxillofac Surg 57:812-817;1999.

17 Chase DC, Hudson JW, Gerard DA, et al. The Christense prosthesis ; A retrospective clinical study, Oral Surgery Oral Medicine Oral Pathology80:273-8:1995 .

18 Rishiraj B, McFadden LR, Treatment of Temporomandibular Joint Ankylosis: A Case Report, J Can Dent Assoc 67(11):65963;2001.

19 MacIntosh RB,The case for autogenous reconstruction of the adult temporomandibular joint. In: Worthington P, Evans JR, eds. Controversies in Oral and Maxillofacial Surgery. Philadelphia: WB Saunders 356-380;1994.

20 Fontenot MG. Temporomandibular joint devices: past present and future. In: Sessle Bl, Bryant PS, Dionne RA, eds. Temporomandibular Disorders and Related Pain Conditions. Seattle: IASP Press; 1995.

21 Mercuri LG: Considering total temporomandibular joint replacement. Journal of Craniomandibular Practice 17:4418,1999 .

22 Figueroa AA, Gans BJ, Pruzansky S. Long term follow up of a mandibular costochondral graft. Oral Surg Oral Med Oral Pathol 58: 257-268; 1984

23 Wen-Ching Ko E, Huang CS, Chen YR. Temporomandibular joint reconstruction in children using costochondral grafts. J Oral Maxillofac Surg 57: 789-798;1999.

24 Kaban LB, Perrott DH, Fisher K. A protocol for the management of temporomandibular joint ankylosis. J Oral Maxilofac Surg
48:1145-1191;1990.

25 Ohara K, Nakumara K, Ohta E. Chest wall deformities and thoracic scoliosis after costal cartilage graft harvesting. Plast Reconstr Surg 99: 1030-1036;1993.

26 Speculand B, Hensher R, Powell D, Total prosthetic replacement of the TMJ: experience with two systems 19881997,The British Journal of Oral \& Maxillofacial Surgery38,360-369;2000.

27 Kent JN, Misiek DJ. Controversies in disc and condyle replacement for partial and total temporomandibular joint reconstruction.In:Worthington P, Evans JR, eds. Controversies in Oral and Maxillofacial Surgery. Philadelphia: WB Saunders 397-435;1994.

28 Saeed NR, McLeod NM, Hensher R, Temporomandibular joint replacement in rheumatoid-induced disease, British Journal of Oral and Maxillofacial Surgery 39, 71-75;2001.

29 Clark MS, Bilateral Temporomandibular Joint Bony Ankylosis Without Mandibular Function: A Case Report, TMJournal:Vol1,No 1: 2001.

30 McBride KL. Total temporomandibular joint reconstruction. In: Worthington P, Evans JR, eds. Controversies in Oral and Maxillofacial Surgery. Philadelphia: WB Saunders 381395; 1994.

31 Henry $\mathrm{CH}$, Wolford LM. Treatment outcomes for temporomandibular joint reconstruction after proplast-teflon implant failure. J Oral Maxillofac Surg 51:352-8;1993.

32 Hensher R. Treatment of TMJ ankylosis. In: Langdon JD, Patel MF, eds. Operative Maxillofacial Surgery. London: Chapman and Hall 175-185;1998.

33 McConnell TP, McCoy JM, Simpson R, Gerard DA, Chase DC. Correlation of histopathological staging of TMJ patients with longitudinal outcome. J Dent Res 70:466:1991.

34 McCoy JM, Gotcher JE, Chase DC. Histologic grading of TMJ tissues in internal derangement. J Craniomand Prac 4:213-8; 1986.

35 McLeod NM,. Saeed NR, Hensher R, Internal derangement of the temporomandibular joint treated by discectomy and hemiarthroplasty with a Christensen fossa-eminence prosthesis, British Journal of Oral and Maxillofacial Surgery 39, 6366;2001.

36 Lindqvist C, Pihakari A, Tasanen A, Hampf G, Autogenous costochondral grafts in temporomandibular joint arthroplasty. A survey of 66 arthroplasties in 60 patients. J Maxillofac Surg: 14 143-149;1986.

37 Popescu V, Vasiliu D. Treatment of temporomandibular joint ankylosis with particular reference to the interposition of fullthickness skin auto transplants. J Oral Maxillofac Surg 5:3$14 ; 1977$.

38 Rowe NL. Ankylosis of the temporomandibular joint.J R Coll Surg Edinb 27:67-79;1982.

39 Kim SG. Treatment of temporomandibular joint ankylosis with temporalis muscle and fascia flap. Int J Oral Maxillofac Surg 30:189-193;2001.

Aria Omrani M.D. is research associate at NanoMedical Studies Association (Isfahan,Iran). His current interest is the biocompatability of alloplastic materials in temporomandibular joint surgery.His scientific articles span a variety of subjects such as pediatrics, neurology and nanomedicine.His latest article, "Thromboembolism events in childhood" has been published in International Pediatrics, Vol 18, No 1(Miami, FL, USA). 